\title{
Flow Field Simulation And Experimental Investigation On Macro Electrolyte Jet Electrochemical Turning of TB6 Titanium Alloy
}

\section{Yang Liu}

Nanjing University of Aeronautics and Astronautics

Ningsong Qu ( $\nabla$ nsqu@nuaa.edu.cn )

Nanjing University of Aeronautics and Astronautics https://orcid.org/0000-0002-0607-0136

Zhi Qiu

Shanghai Academy of Spaceflight Technology (SAST)

\section{Research Article}

Keywords: Macro electrochemical turning, Titanium alloy, Rotating parts, Flow field simulation

Posted Date: October 27th, 2021

DOI: https://doi.org/10.21203/rs.3.rs-1012053/v1

License: (c) (1) This work is licensed under a Creative Commons Attribution 4.0 International License. Read Full License

Version of Record: A version of this preprint was published at The International Journal of Advanced Manufacturing Technology on February 25th, 2022. See the published version at https://doi.org/10.1007/s00170-022-08956-0. 


\title{
Flow field simulation and experimental investigation on macro electrolyte jet electrochemical turning of TB6 titanium alloy
}

\author{
Yang Liu ${ }^{\mathrm{a}, \mathrm{b}}$, Ningsong $\mathrm{Qu}^{\mathrm{a} *}, \mathrm{Zhi} \mathrm{Qiu}^{\mathrm{c}}$
}

${ }^{a}$ National Key Laboratory of Science and Technology on Helicopter Transmission, Nanjing University of Aeronautics and Astronautics, Nanjing, 210016, China.

${ }^{\mathrm{b}}$ School of Mechanical Engineering, Jiangsu University, Zhenjiang, 212013, China.

c Shanghai Aerospace Electronic Technology Institute, Shanghai Academy of Spaceflight Technology (SAST), Shanghai, 201109, China.

*Corresponding author. E-mail: nsqu@ nuaa.edu.cn; Tel: +8602584893870; Fax: +8602584895912 (N. Qu).

\begin{abstract}
Electrolyte jet electrochemical turning is an effective method to realize high-quality machining of titanium alloy rotating components; however, minimal research has been carried out in this field. This is because it is difficult to control the machining flow field, which leads to poor machining surface quality. In this work, numerical simulations were used to optimize the machining flow field and reduce the proportion of gas that mixed into the machining area. This can promote participation of the tool electrode tip in the electrochemical reaction and improve the machining efficiency. The effectiveness of the optimized machining flow field for jet electrochemical turning was verified experimentally. The results showed that all three kinds of revolving TB6 titanium alloy samples with different structures could maintain the original contour shape, with a contour error $<1 \%$ and a machined surface roughness reaching Ra $2.414 \mu \mathrm{m}$. The results demonstrate the application potential of the jet electrochemical turning process.
\end{abstract}

Keywords: Macro electrochemical turning; Titanium alloy; Rotating parts; Flow field simulation

\section{Introduction}

Rotating components in the aerospace field need to work at high speeds, temperatures, pressure and in harsh environments for extended durations [1,2]. Therefore, these components need to have high strength and good corrosion resistance [3-5]. To achieve these performance characteristics, these components are usually made of difficult-to-cut materials such as titanium alloy. Additionally, to ensure stability under continuous operation, they also have stringent requirements for shape accuracy, and machining of these parts poses significant challenges for traditional machining methods [6-8].

At present, the main machining processes for revolving parts includes traditional cutting machining, electrical discharge machining (EDM), and electrochemical machining (ECM). Traditional cutting machining faces many difficulties in machining these revolving parts, such as a high machining temperature, severe work hardening, and serious tool loss. EDM is limited by thermal damage to the machined surface, such as the metamorphic layer and micro-cracking. ECM is a non-traditional machining method that uses electrochemical dissolution to remove materials. It has the advantages of a high machining efficiency, good surface quality, no tool loss, 
and no cutting force. Therefore, ECM is a promising avenue to realize high-efficiency and high-quality machining of aerospace revolving parts.

Electrochemical turning (ECT) is an important research direction in ECM, and it is suitable for machining rotating parts. During ECT, the workpiece rotates at a high speed while the tool electrode remains stationary or moves at a low speed relative. The workpiece and tool electrode are respectively connected with the positive and negative electrodes of a DC power supply, and the electrolyte quickly flows through the machining gap.

At present, some studies have applied ECT for surface finishing and micro machining. Pa et al. proposed a new ECT method that used a disc tool electrode to polish a steel cylindrical surface [9]. Eltaweel et al. combined ECT with abrasive flow finishing and found this hybrid method had a good machining effect on aluminum matrix composites [10]. Wang et al. used ECT to obtain a $20 \mu \mathrm{m}$ diameter microelectrode [11]. Haridy et al. carried out research on ECT and optimized the machining parameters via DOE [12]. Kunieda et al. used a rectangular electrolyte jet instead of a cylindrical electrolyte jet to realize cutting machining of rotating components [13]. Pa and $\mathrm{P}$. introduced a magnetic assistant system into ECT, which addressed the issue of electrolytic products adhering to the tool electrode [14]. Martin et al. produced groups of micro grooves via ECT on a stainless steel cylindrical surface [15]. Sharma et al. established a mathematical model to study metal wire electrode ECT and predict the variation law of the machined surface [16]. In addition, Sharma et al. used metal wire electrode ECT to process thread structures on various materials. They demonstrated that metal wire electrode ECT was a universal and practical technique [17]. Kendall et al. found that ECT could play an important role in machining of micro parts via comprehensive analysis of jet electrochemical machining [18].

In addition to surface finishing and micro machining, ECT can also be used for material removal during rough machining of rotating parts. Eltaweel combined ECT with magnetic grinding to improve the material removal rate and reduce the machined surface roughness [10]. Zanjani et al. designed a simple real-time detection sensor system for the machining gap in ECT and for machined 316 stainless steel parts with a non-circular cross section [19].

Although electrolyte jet ECT has significant advantages for the rapid removal of surface materials of large revolving parts, there has been minimal research on its application to macro rotating components. In particular, it should be noted that research on ECT of titanium alloy is scarce; this is because titanium alloy is particularly sensitive to changes of the flow field. Ge et al. carried out research on ECT of a superalloy cylindrical surface [20-23]. They used a tubular tool electrode with an internal spray electrolyte to realize efficient removal on a large cylindrical surface. Through flow field simulation, Fu et al. studied the electrochemical turning process of stainless steel revolving parts [24], and the influence of the internal channel structure on the flow field distribution was analyzed and the tool electrode was optimized.

There remain two aspects that are lacking in electrolyte jet ECT research. Few studies have focused on macro electrolyte jet ECT of more complex contour parts and on ECT of titanium alloy. 
In the aerospace field, large-scale titanium alloy revolving parts are very common; hence, it is of interest to study high-efficiency and high-quality electrolyte jet ECT with rotating titanium alloy parts.

To address the above two issues, the following work was done for this paper. First, with the help of numerical simulations, the gas-liquid two-phase flow field distribution was analyzed and the flow field distribution was optimized. The optimized flow field could promote participation of the tool electrode end in the electrochemical reaction and then improve the electric-field intensity; additionally, it also reduced air mixing and improved the stability of the flow field. TB6 titanium alloy has serious passivation issues during ECM $[25,26]$ and previous studies on the growth and fracture mechanism of the passive film were carried out under the condition that the workpiece remained stationary or moved at a low speed [27, 28]. In electrolyte jet ECT, the workpiece rotates at a high speed and the workpiece surface experiences rapid cycling from the machining area to the non-machining area. Therefore, it is of significance to study the characteristics of the formation and fracture of the passive films under these new machining condition. Finally, the influence of different parameters was explored, and electrolyte jet ECT experiments involving different rotating samples were carried out.

\section{Description of the method}

The principle of electrolyte jet ECT is shown in Fig. 1. The hollow metal nozzle is connected with the negative pole of the power supply as the tool cathode, and the revolving part was connected with the positive pole of the power supply as the anode. The electrolyte flows out from the inside of the tool electrode and is sprayed on the workpiece to connect the anode and cathode as a conductive medium. The initial machining gap $\Delta_{0}$ is set before machining. During the machining process, the workpiece rotates at high speed and the tool electrode moves along the radial direction of the workpiece at a constant low speed, and then rapid dissolution occurs on the workpiece surface to realize high-speed material removal.

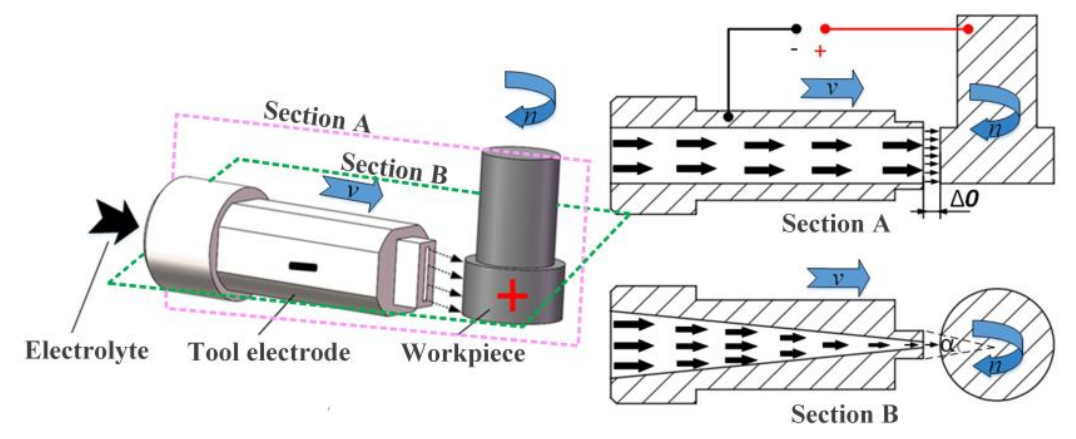

Fig. 1 Schematic diagram of electrolyte jet ECT

According to Faraday's first law, the mass of the material at a two-phase interface (such as the metal/solution surface) is directly proportional to the amount of electricity. Therefore, the volume $V$ of the dissolved anodic metal during ECM can be expressed as:

$$
V=M / \rho=k I t / \rho=\omega I t,
$$

where $M$ is the metal dissolved quality, $k$ is the mass of dissolved elements per unit electric 
quantity, $\rho$ is the density of the workpiece, $I$ is current, $t$ is machining time, and $\omega$ is volume electrochemical equivalent of elements.

The surface area of the cylinder is $S$, and the dissolution rate of the anode metal is given by:

$$
v_{\mathrm{a}}=V / S t=\eta \omega I t=\eta \omega i \cdot \alpha / 2 \pi,
$$

where $v_{\mathrm{a}}$ is electrochemical machining speed, $\eta$ is the current efficiency, $i$ is the current density, and $\alpha$ is the angle of the tool cathode surrounding the workpiece.

\section{Numerical simulation of flow field}

The flow field plays a decisive role in the machining efficiency and quality of electrolyte jet ECT. A uniform and stable flow field can effectively wash away the machined products. When designing the flow field, providing sufficient and uniform electrolyte for the machining area is crucial. In this work, a flow field simulation model is established and meshed using simulation software and flow field simulations for electrolyte jet ECT were carried out. The structure of the tool electrode was analyzed and optimized using the simulation results.

\subsection{Establishment of simulation model}

The three-dimensional flow field simulation model of scheme one is shown in Fig. 2; the red surface is the electrolyte pressure inlet and the blue and green surfaces are the tool electrode wall and the machined workpiece surface, respectively. The electrolyte outlet is set around the machining gap (blue surface in Fig. 2). To facilitate observation, section A and section B are set in a three-dimensional fluid model. The electrolyte flow rate and pressure distribution can be analyzed using the flow field distribution characteristics in the different sections. Mesh generation is a key step for flow field simulation, and its quality directly determines the calculation speed and accuracy. Here, based on theoretical analysis of the flow field characteristics and previous experience of electrolyte jet ECT, the three-dimensional flow field model is divided into tetrahedral meshes. The flow field has a large gradient at the wall boundary because of the effect of the viscous liquid; hence, the expansion layer is set on the wall of the model for local densification, as shown in Fig. 3.
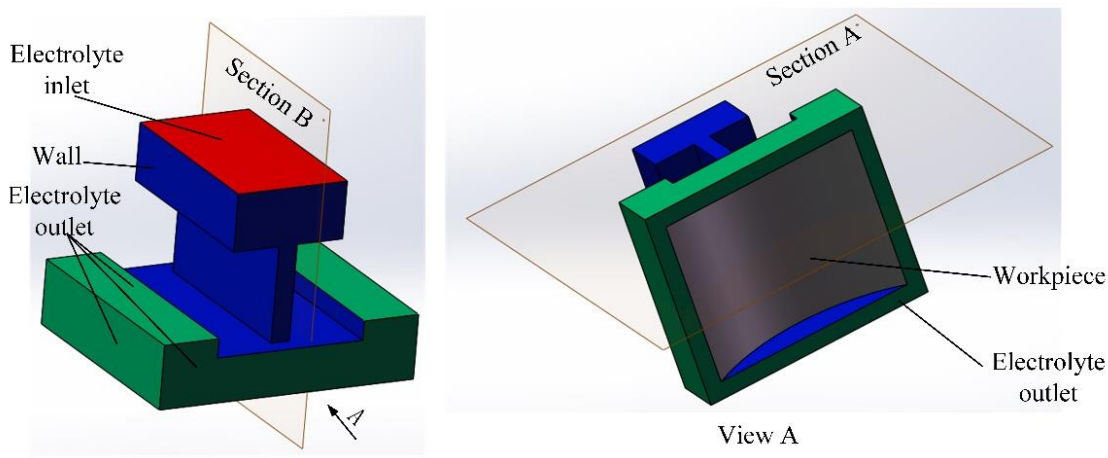

Fig. 2 Three-dimensional flow field simulation model 

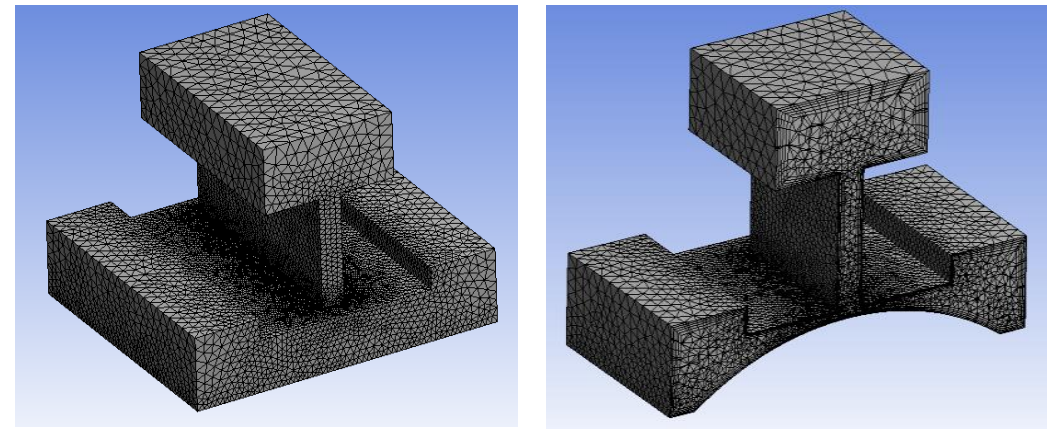

Fig. 3 Mesh of flow field simulation model

During the machining process, the electrolyte washed the machined surface at high speed, which enabled quick removal of the machining products, bubbles, and heat. To facilitate the calculations, the influence of the temperature change, machining products, and bubble was not considered in the numerical simulations. The electrolyte fluid was assumed to be a continuous incompressible viscous fluid. The fluid flow was constrained by the law of conservation of mass and momentum.

The conservation equation of mass is:

$$
\frac{\partial \rho}{\partial t}+\frac{\partial\left(\rho u_{i}\right)}{\partial x_{i}}=S_{m}
$$

where $\rho$ is the density of fluid, $t$ is time, $u_{i}$ is velocity tensor, $x_{i}$ is coordinate tensor, and $S_{m}$ is the mass added to the continuous phase from the dispersed secondary phase.

The momentum conservation equation is:

$$
\frac{\partial\left(\rho u_{i}\right)}{\partial x_{i}}+\frac{\partial\left(\rho u_{i} u_{j}\right)}{\partial x_{j}}=-\frac{\partial \rho}{\partial x_{i}}+\frac{\partial \tau_{i j}}{\partial x_{j}}+\rho g_{i}+F_{i},
$$

where $u_{i}$ and $u_{j}$ is the velocity tensor, $x_{i}$ and $x_{j}$ is the coordinate tensor, $\rho$ is the static pressure, $\rho g_{i}$ is the gravity volume force, $F_{i}$ is other volumetric forces, and $\tau_{i j}$ is the stress tensor in the ij plane;

Liquid flow includes regular laminar flow and irregular turbulent flow, which are distinguished by the Reynolds number Re. When Re is $<2300$, the flow is laminar and when Re is $>2300$, the flow is turbulent. The formula for calculation of Re is:

$$
\operatorname{Re}=\frac{u D_{h}}{v}
$$

where $u$ is electrolyte flow rate, $v$ is kinematic viscosity of the electrolyte, and $D_{h}$ is the hydraulic diameter of channel section.

For non-circular pipes, the hydraulic diameter is calculated according to the following formula: 


$$
D_{h}=\frac{4 A_{e}}{S},
$$

where $A_{e}$ is the cross-sectional area of the pipe and $S$ is the perimeter of the pipe section.

Under actual machining conditions, it is estimated that the electrolyte flow rate in the pipeline is $>5 \mathrm{~m} / \mathrm{s}$ and the kinematic viscosity is $0.8 \times 10^{-6} \mathrm{~m}^{2} / \mathrm{s}$. The hydraulic diameter $D_{h}$ is calculated to be $10.9 \mathrm{~mm}$ using formula (6).

According to formula (5), the electrolyte in this work has a turbulent flow state with a high Reynolds number, and the standard k- $\varepsilon$ model is widely used for turbulent flow of pipeline fluid. The turbulent kinetic energy equation and dissipation rate equation are as follows.

Turbulent kinetic energy equation:

$$
\frac{\partial(\rho k)}{\partial t}+\frac{\partial\left(\rho k u_{i}\right)}{\partial x_{i}}=\frac{\partial}{\partial x_{j}}\left[\left(\mu+\frac{\mu_{t}}{\sigma_{k}}\right) \frac{\partial k}{\partial x_{j}}\right]+G_{k}-\rho \varepsilon .
$$

Dissipation rate equation:

$$
\frac{\partial(\rho \varepsilon)}{\partial t}+\frac{\partial\left(\rho \varepsilon u_{i}\right)}{\partial x_{i}}=\frac{\partial}{\partial x_{j}}\left[\left(\mu+\frac{\mu_{t}}{\sigma_{\varepsilon}}\right) \frac{\partial \varepsilon}{\partial x_{j}}\right]+C_{1 \varepsilon} \frac{\varepsilon}{k} G_{k}-C_{2 \varepsilon} \rho \frac{\varepsilon^{2}}{k},
$$

where $k$ is the turbulent kinetic energy of the fluid, $\varepsilon$ is the dissipation rate, $\mu$ is the effective viscosity coefficient, coefficients $C_{1 \varepsilon}$ and $C_{2 \varepsilon}$ are 1.44 and 1.92, and the empirical constants $\sigma_{k}$ and $\sigma_{\varepsilon}$ are 1 and 1.3 , respectively.

In addition, the turbulent kinetic energy generation term $g$ caused by the average velocity gradient $G_{k}$ and turbulent viscosity $\mu_{t}$ is calculated as follows:

$$
\begin{gathered}
G_{k}=\mu_{t}\left(\frac{\partial u_{i}}{\partial x_{i}}+\frac{\partial u_{j}}{\partial x_{j}}\right) \frac{\partial u_{i}}{\partial x_{j}}, \\
\mu_{t}=\rho C_{\mu} \frac{k^{2}}{\varepsilon}
\end{gathered}
$$

where the coefficient constant $C_{\mu}$ is set to 0.09 .

The parameters and boundary conditions of the fluid simulation model are shown in Table 1.

Table 1 Parameters and boundary conditions of the fluid simulation model

\begin{tabular}{ll}
\hline Parameter & Value \\
\hline Electrolyte & $20 \% \mathrm{NaNO}_{3}$ \\
Initial machining gap & $0.3 \mathrm{~mm}$ \\
Inlet pressure & $0.6 \mathrm{MPa}$ \\
Outlet pressure & $0.1 \mathrm{MPa}$ \\
Electrolyte temperature & $40{ }^{\circ} \mathrm{C}$ \\
\hline
\end{tabular}




\subsection{Analysis and optimization of simulation results}

The numerical simulation results of scheme one are shown in Fig. 4. The velocity distribution and pressure distribution in section $\mathrm{A}$ are shown in Fig. $4 \mathrm{a}$ and $4 \mathrm{~b}$, respectively. The simulation results show that the pressure in the liquid outlet gap is high while the pressure in the other areas is low, and the flow rate changes over a wide range. The surrounding air can easily enter the machining gap and form a disordered flow field, such as cavitation or a vortex. The velocity distribution and pressure distribution in section B are shown in Fig. 4c and 4d, respectively. The electrolyte pressure distribution in the machining gap along the axis of the workpiece remains almost zero, so it can easily mix with the outside air. The air volume distribution in the machining gap was calculated, as shown in Fig. 4e and 4f. The electrolyte fills the inner channel of the tool electrode but cannot fill the machining gap. A large amount of air is mixed in the machining area, and the volume fraction of air on the bottom of the tool electrode reaches $100 \%$. Therefore, the bottom surface of the cathode cannot participate in machining because of a lack of conductive medium, which would significantly reduce the machining electric field and machining efficiency.

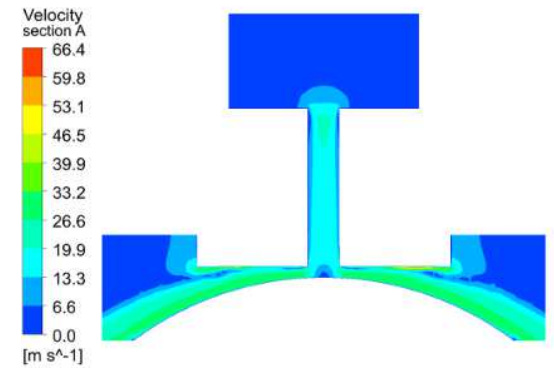

(a) Velocity distribution in section A

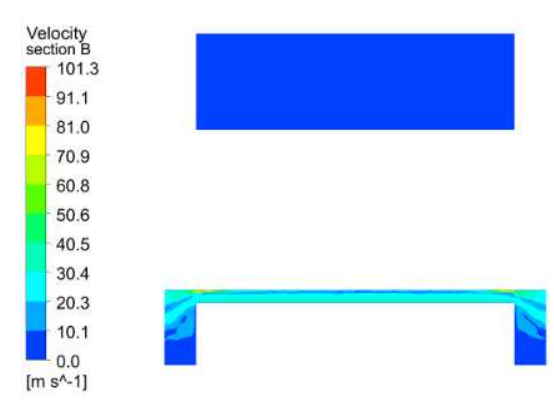

(c) Velocity distribution in section B

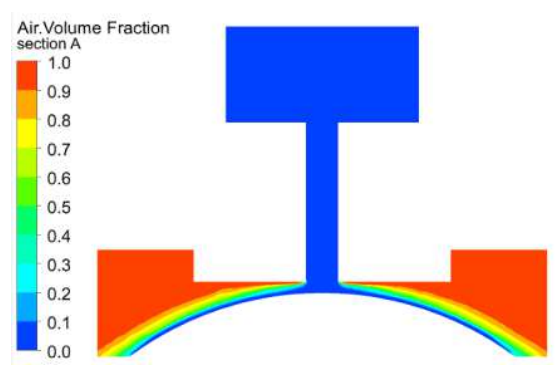

(e) Air volume distribution in section A

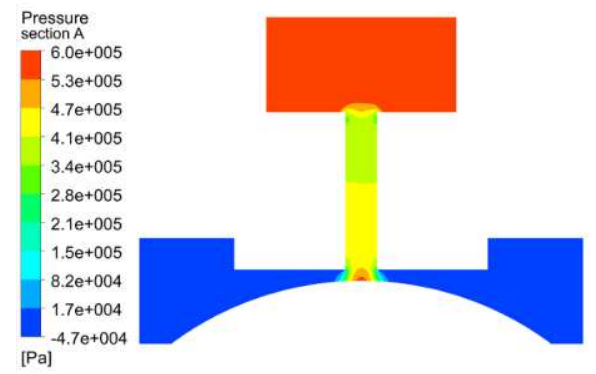

(b) Pressure distribution in section $\mathrm{A}$

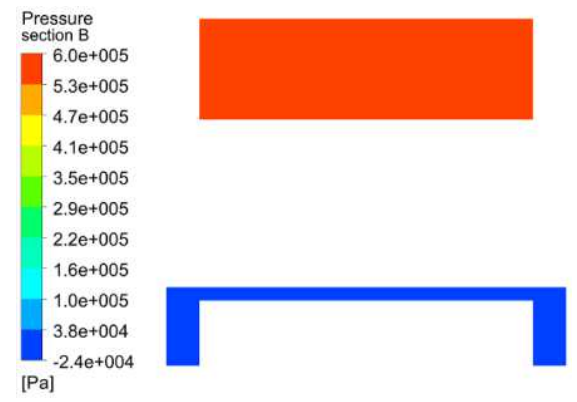

(d) Pressure distribution in section B

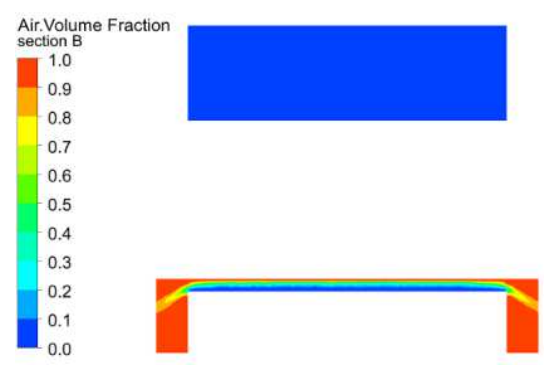

(f) Air volume distribution in section B

Fig. 4 Flow field simulation results in scheme one

To further study the flow field characteristics of scheme one, the initial boundary conditions are changed to analyze whether flow field defects could be eliminated. 


\section{(1) Influence of machining gap}

The same electrolyte inlet pressure of 0.6 MPa was used and the machining gap (MG) was set to 0.2 and $0.4 \mathrm{~mm}$. The simulation results are shown in Fig. 5. Compared with the simulation results in Fig. 4, the electrolyte pressure in the tool electrode decreased correspondingly with increasing machining gap, but the air volume distribution displayed no obvious change. Therefore, the flow field distribution was less affected by a change of the machining gap. However, because a large amount of air mixes into the bottom of the tool electrode, the drawback that the tool electrode end does not participate in the ECM remains.

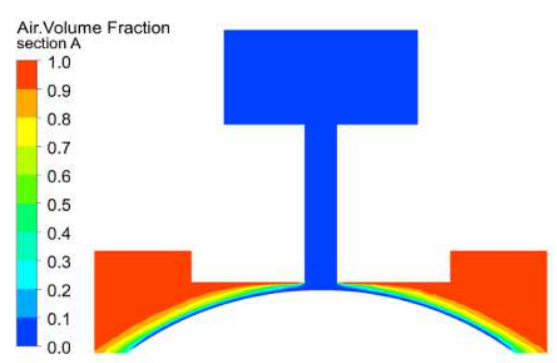

(a) Gas volume distribution with MG $0.2 \mathrm{~mm}$

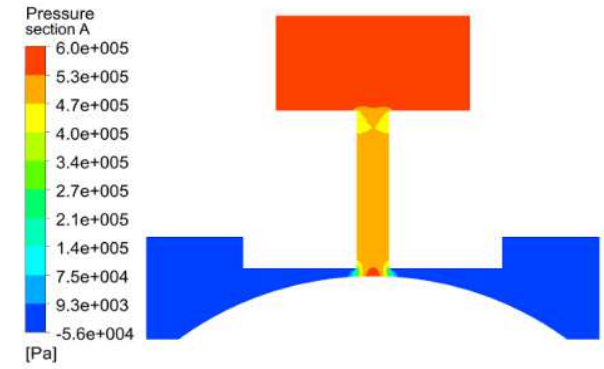

(b) Pressure distribution with MG $0.2 \mathrm{~mm}$

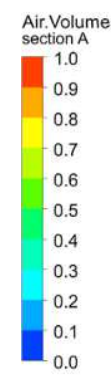

(c) Gas volume distribution with MG $0.4 \mathrm{~mm}$

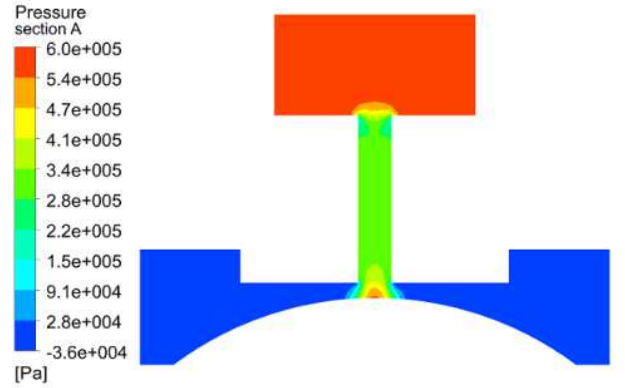

(d) Pressure distribution with MG $0.4 \mathrm{~mm}$

Fig. 5 Numerical simulation results of the flow field for different machining gaps

\section{(2) Influence of electrolyte inlet pressure}

The machining gap was maintained at $0.3 \mathrm{~mm}$ and the electrolyte inlet pressure was set at 0.4 and $0.8 \mathrm{MPa}$, respectively. The flow field simulation results are shown in Fig. 6 . 
Gas volume distribution

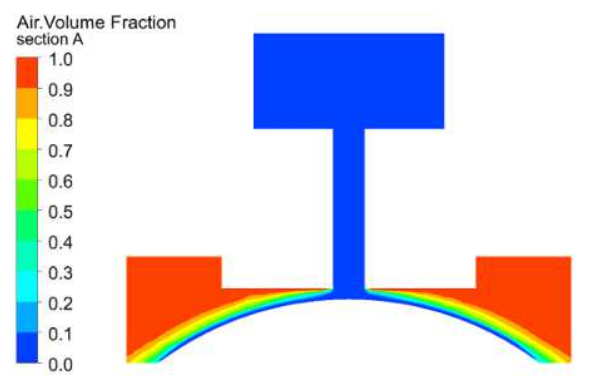

(a) Inlet pressure $0.4 \mathrm{MPa}$

Gas volume distribution

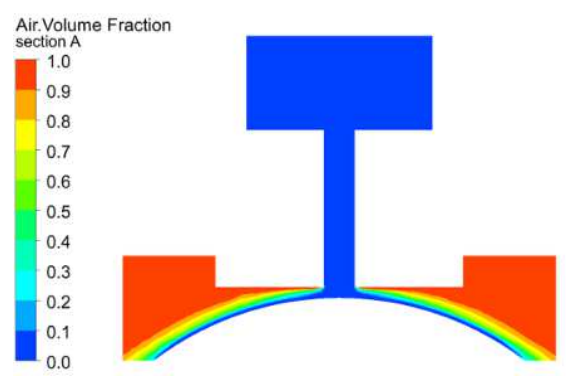

(b) Inlet pressure $0.8 \mathrm{MPa}$

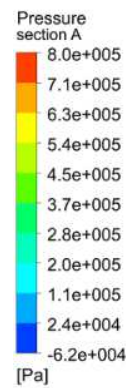

Pressure distribution
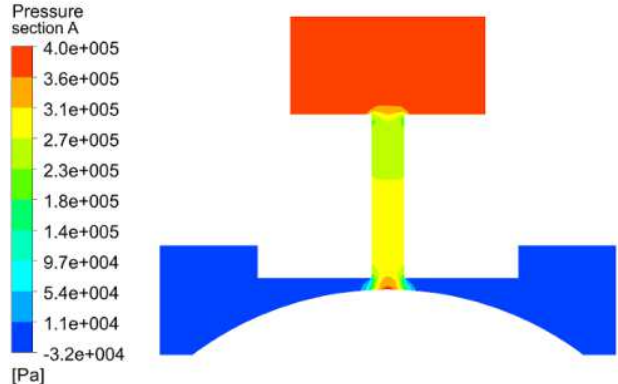

Pressure distribution

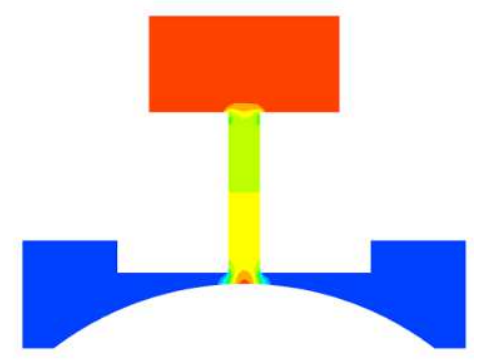

Fig. 6 Flow field simulation results for different electrolyte inlet pressures

Compared with the simulation results in Fig. 4, the electrolyte pressure in the tool electrode increased correspondingly with increasing electrolyte inlet pressure but the pressure in the machining gap remained at zero and the air volume distribution displayed no obvious change. Therefore, the flow field distribution in the machining gap was less affected by the electrolyte inlet pressure.

In conclusion, adjusting the machining gap and changing the electrolyte inlet pressure could not effectively eliminate flow field defects. To promote participation of the electrode end in the electrochemical reaction and finally improve the electrochemical machining efficiency, it is necessary to improve the structure of the tool electrode rather than only optimizing the machining parameters.

To confine the electrolyte to the tool electrode tip and reduce mixing of external air, two outlet slits were symmetrically added at the sides of the original outlet slit, which is referred to as scheme B and shown in Fig. 7a. The flow field simulation process is the same as scheme A, and the numerical simulation results are shown in Fig. 7b-e. As shown in Fig.7b and 7c, compared with scheme one, the pressure at the machining gap corresponding to area II and III significantly increased. The air volume fraction in those areas is zero, indicating that outside air is not mixed in. As shown in Fig. $7 \mathrm{c}$ and $7 \mathrm{~d}$, along the axis of the workpiece, the pressure at the machining gap corresponding to area II and III is still large, and the air volume is also zero. Therefore, region II and III at the bottom of the tool electrode can normally participate in electrochemical machining, which is of significance for improving the machining efficiency. 


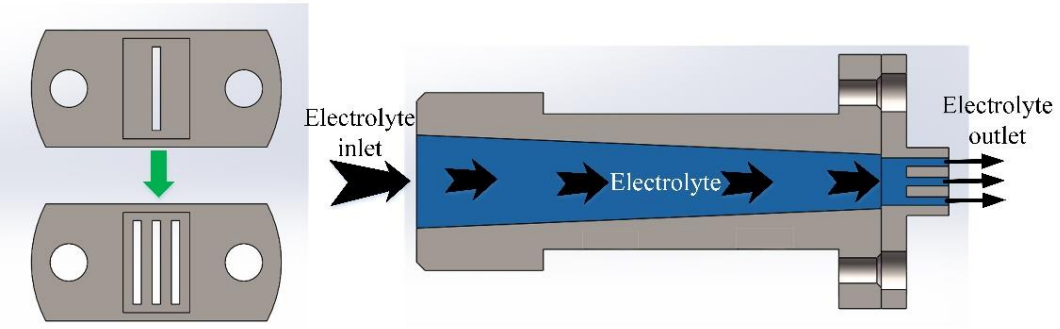

(a) Schematic diagram of tool electrode structure.

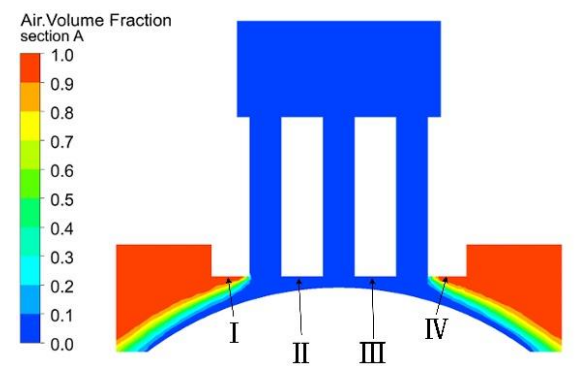

(b) Gas volume distribution in section $\mathrm{A}$

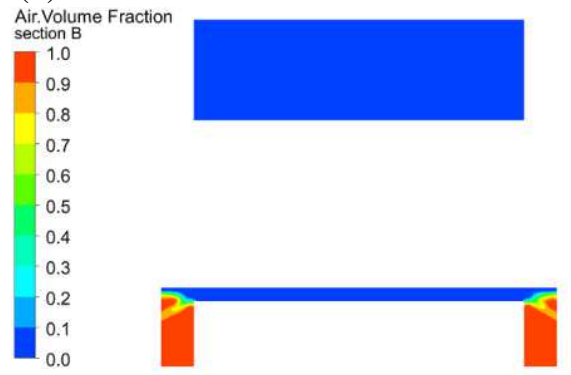

(d) Gas volume distribution in section B

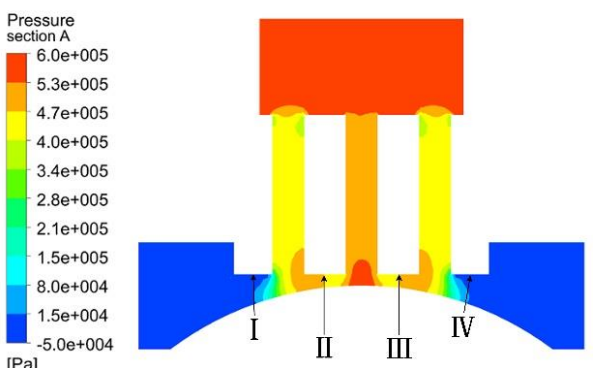

(c) Pressure distribution in section A

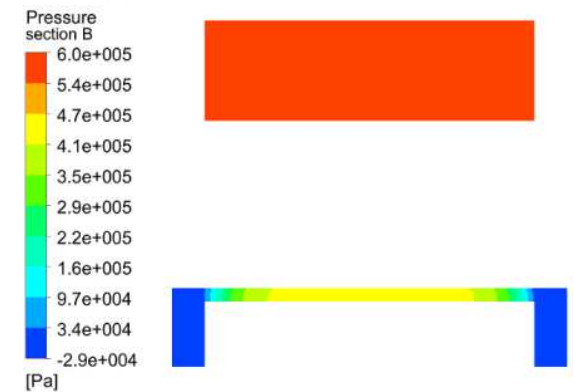

(e) Pressure distribution in section B

Fig. 7 Design scheme and flow field simulation of scheme two

According to the simulation results in Fig. 7, it can be hypothesized that the pressure in the area between two outlet slits is sufficiently high to force the machining area be filled with electrolyte. Therefore, even if the middle outlet slit is removed, the machining area will still be filled with electrolyte. In addition, because the workpiece surface is an arc and the bottom of the tool electrode is a plane, the machining gap in the circumferential direction is uneven. The average machining gap is large, which leads to a low machining efficiency because of the low current density distribution. To improve machining efficiency, the bottom surface of the tool electrode was designed in the shape of an arc. This design is called scheme three and is shown in Fig. 8. According to the flow field simulation results for scheme three, it can be seen that reducing the middle outlet slit would not affect the pressure and air volume distribution in the machining gap. Compared with scheme two, the increase in the conductive metal area in scheme three is helpful for improving machining efficiency. In addition, no electrolyte is distributed in region I and IV, which means that these areas would not participate in the electrochemical reaction. 


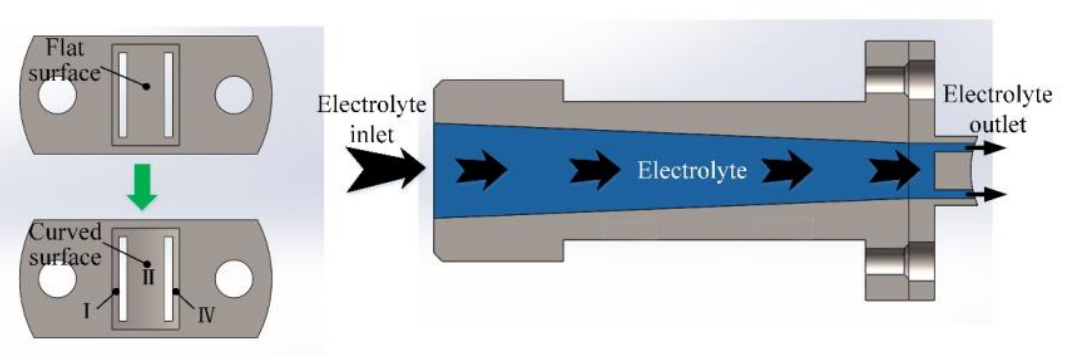

(a) Schematic diagram of the tool electrode.

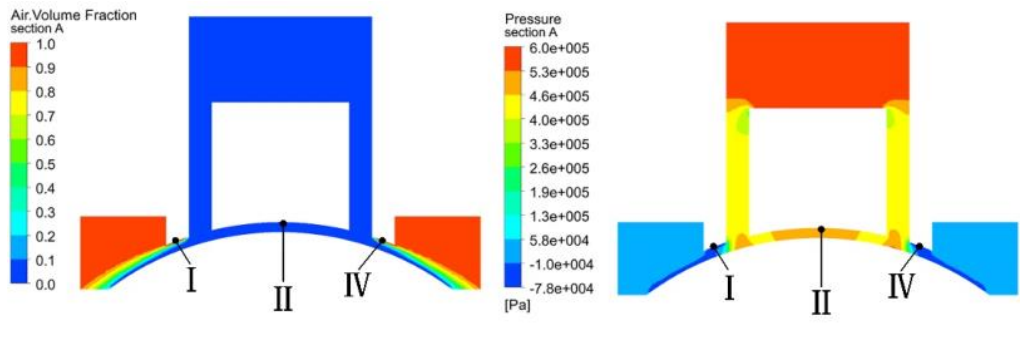

(b) Gas volume distribution

(c) Pressure distribution

Fig. 8 Design scheme and flow field simulation of scheme three

\section{Experimental}

\subsection{Experimental setup}

The electrolyte jet ECT system includes the equipment body, a power supply system, an electrolyte system, and a motion control system. The schematic diagram of the system and photos of the core components are shown in Fig. 9 and Fig. 10. The equipment body is composed of the base, a marble platform, an electrochemical reaction tank, and a rotating spindle. The electrochemical reaction tank, as the place where the electrochemical dissolution reaction occurs, is designed as a closed space to prevent the electrolyte from polluting the surrounding instruments. The tank is fixed on an XY motion slide that can move freely, and it is constructed using transparent plexiglass, which allows for observation of the machining process. Three drainage holes were added to the left side of the tank body, which can direct turbid electrolyte to the turbid electrolyte tank. A conductive copper block is installed in the middle of the machining platform and connected to the negative pole of DC power supply. The cover plate of the working tank is composed of two parts; the left cover plate has an air outlet and the right cover plate is equipped with an exhaust fan, which can eliminate hydrogen, chlorine, and other gases produced during electrochemical machining. 


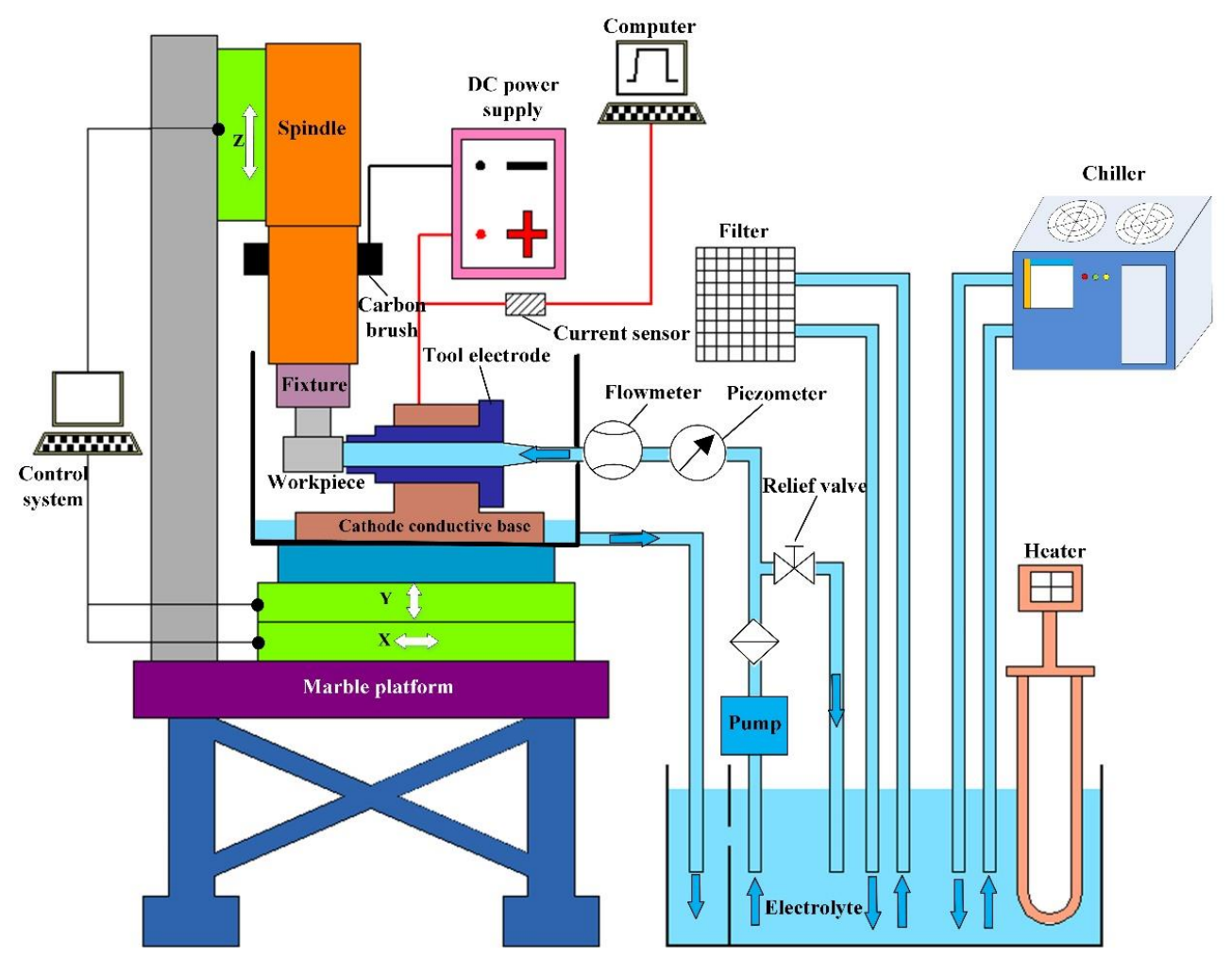

Fig. 9 Schematic diagram of electrolyte jet ECT system

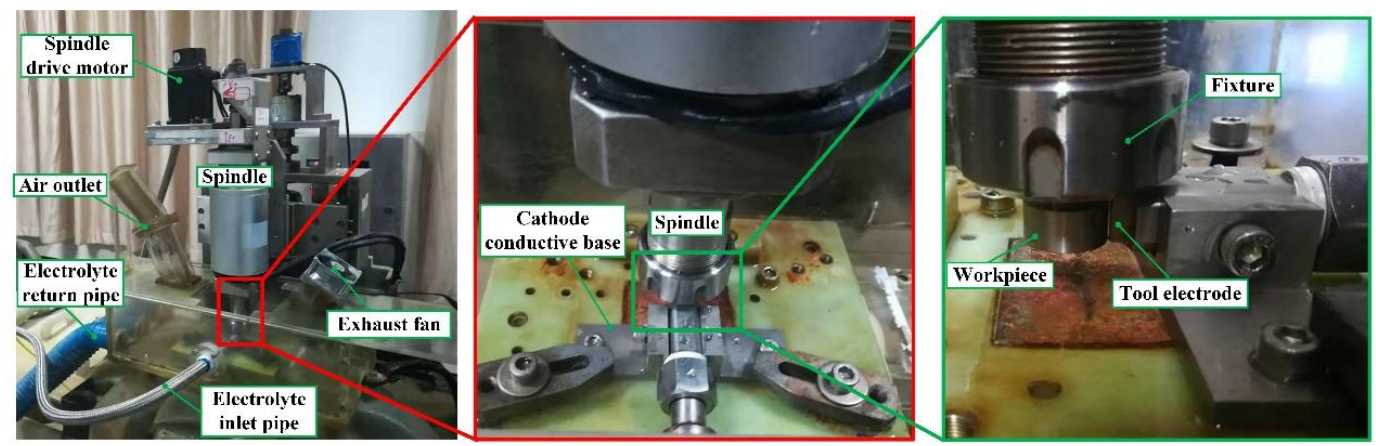

Fig. 10 Photos of the core components

\subsection{Experimental procedure}

To study the characteristics of electrolyte jet ECT of titanium alloy TB6, a large number of machining experiments were carried out. The machining parameters are shown in Table 2. The workpiece blank was a cylinder made of TB6 titanium alloy with a diameter of $\Phi 20 \mathrm{~mm}$. TB6 titanium alloy has excellent material characteristics, such as a high specific strength, excellent stamping performance, low forging temperature, and strong stress corrosion resistance. It is mainly used for manufacturing integral structural parts for helicopters and fighter planes, such as hub centric parts, aircraft compressor blades, and spring fasteners. The chemical composition and physical properties of TB6 titanium alloy are shown in Table 3 and Table 4, respectively. 
Table 2 Main experimental parameters for electrolyte jet ECT

\begin{tabular}{ll}
\hline Parameter & Value \\
\hline Electrolyte & $10 \mathrm{wt} \% \mathrm{NaNO}_{3}$ \\
Electrolyte inlet pressure & $0.8 \mathrm{MPa}$ \\
Electrolyte temperature & $30^{\circ} \mathrm{C}$ \\
Machining voltage & $16,20,24,28,32 \mathrm{~V}$ \\
Tool electrode dimensions & $8 \mathrm{~mm} \times 10 \mathrm{~mm}$ \\
Workpiece rotating speed & $100,300,500,700,900 \mathrm{rpm}$ \\
Initial machining gap & $0.3 \mathrm{~mm}$ \\
\hline
\end{tabular}

Table 3 Elemental composition of TB6 titanium alloy (mass fraction wt\%)

\begin{tabular}{cccccccccc}
\hline $\mathrm{Al}$ & $\mathrm{V}$ & $\mathrm{Fe}$ & $\mathrm{Ti}$ & $\mathrm{C}$ & $\mathrm{N}$ & $\mathrm{H}$ & $\mathrm{Y}$ & $\mathrm{O}$ & Others \\
\hline $2.6-3.4$ & $9.0-11.0$ & $1.6-2.2$ & Balance & 0.05 & 0.05 & 0.015 & 0.005 & 0.13 & 0.3 \\
\hline
\end{tabular}

Table 4 Physical properties of TB6 titanium alloy

\begin{tabular}{cccccc}
\hline Density & Melting point & Thermal conductivity & $\begin{array}{c}\text { Elastic } \\
\text { modulus }\end{array}$ & $\begin{array}{c}\text { Yield } \\
\text { strength }\end{array}$ & $\begin{array}{c}\text { Tensile } \\
\text { strength }\end{array}$ \\
\hline $4.62 \mathrm{~g} / \mathrm{cm}^{3}$ & $1636-1664{ }^{\circ} \mathrm{C}$ & $8.47-15.2 \mathrm{~W} / \mathrm{m} \cdot \mathrm{K}$ & $104 \mathrm{GPa}$ & $1200 \mathrm{MPa}$ & $100 \mathrm{GPa}$ \\
\hline
\end{tabular}

\subsection{Measurements and observation}

The three-dimensional contour of the machined sample was measured by a coordinate measuring machine (TESA Micro-Hite 3D, TESA, Switzerland). The machining current signal in the experiments was collected in real time via a data recorder (HIOKI 9335, HIOKI, Japan). The macro morphologies of the machined surfaces were observed using an optical microscope (DVM5000, Leica, Germany). Mass weighing was carried out using a Mettler electronic balance. The surface roughness Ra was measured via a Taylor Hobson surface profiler. After machining, the workpiece was cleaned with an alcohol solution. After drying, the mass was weighed to calculate the material removal mass $\Delta m$. The material removal rate $(M R R)$ was calculated using formula 11 .

$$
M R R=\Delta m / t
$$

where $\Delta m$ is the workpiece material removed by machining and $t$ is machining time.

\section{Results and discussion}

\subsection{Influence of machining parameters on experimental results}

\section{(1) Machining voltage}

Based on a large number of previous studies, short circuit discharge often occurs during the machining process when the machining voltage exceeds $32 \mathrm{~V}$, which seriously damages the tool electrode and workpiece surface. Therefore, in this work, the machining voltage was controlled to below $32 \mathrm{~V}$. Different machining voltages were selected for the experiments in the range of 
20-32 V. The initial machining gap was $0.3 \mathrm{~mm}$, the rotation speed of workpiece was $900 \mathrm{rpm}$, the cathode feed speed was 0 , the electrolyte pressure was $0.8 \mathrm{MPa}$, and the machining time was 7 min. The macro morphology of the workpiece after machining is shown in Fig. 11, and the MRR and surface roughness Ra are shown in Fig. 12.

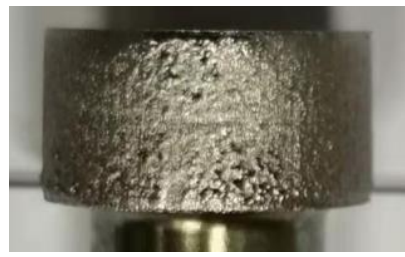

(a) $20 \mathrm{~V}$

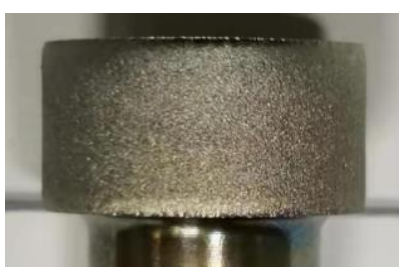

(c) $28 \mathrm{~V}$

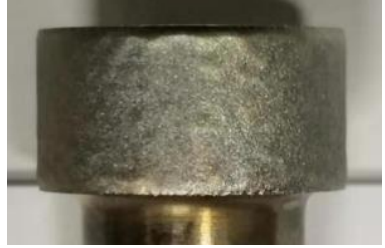

(b) $24 \mathrm{~V}$

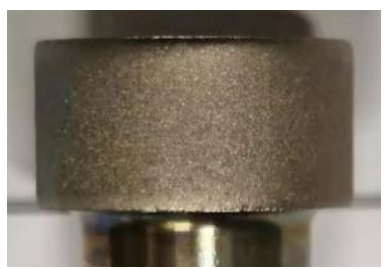

(d) $32 \mathrm{~V}$

Fig. 11 Workpiece surface morphology for different machining voltages

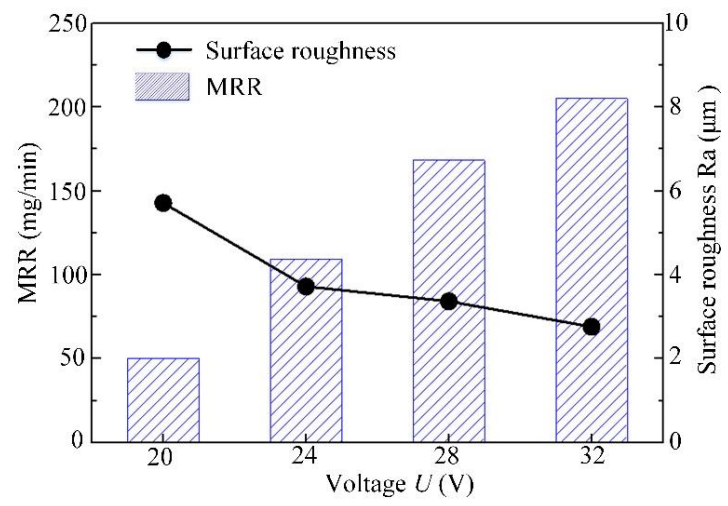

Fig. 12 Effect of machining voltage on MRR and surface roughness

When the used machining voltage was $20 \mathrm{~V}$, many small protrusions could be observed on the machined surface, and the surface roughness was Ra $5.716 \mu \mathrm{m}$. When the machining voltage reached $24 \mathrm{~V}$, the small protrusions disappeared and the surface roughness was reduced to Ra $3.725 \mu \mathrm{m}$. When the machining voltage increased to $32 \mathrm{~V}$, the surface roughness was the lowest (Ra $2.762 \mu \mathrm{m})$ while the MRR reached the highest value $(205.2 \mathrm{mg} / \mathrm{min})$. In conclusion, with increasing machining voltage, the surface roughness decreased and MRR increased, which demonstrated that a high machining voltage was beneficial for improving the machining efficiency and surface quality.

\section{(2) Rotating speed of workpiece}

Based on previous experimental research, the MRR and surface roughness remained basically unchanged when the rotating speed of the workpiece exceeded $900 \mathrm{rpm}$; hence, the workpiece rotating speed was set to below $900 \mathrm{rpm}$. Here, different rotational speeds were selected for the workpiece. The initial machining gap was $0.3 \mathrm{~mm}$, the machining voltage was $32 \mathrm{~V}$, the tool 
cathode feed rate was 0 , the electrolyte pressure was $0.8 \mathrm{MPa}$, and the processing time was 7 min. The macro morphology of the workpiece surface after the experiment is shown in Fig. 13. The machined surface was detected and the micro morphology was observed via SEM, and the results are shown in Fig. 14. The relationship between the MRR, surface roughness, and workpiece rotating speed is shown in Fig. 15.

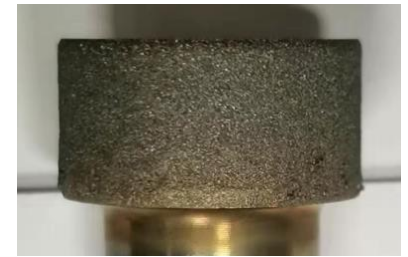

(a) $100 \mathrm{rpm}$

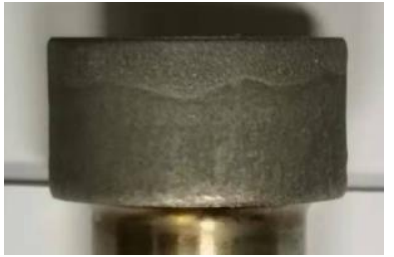

(b) $300 \mathrm{rpm}$

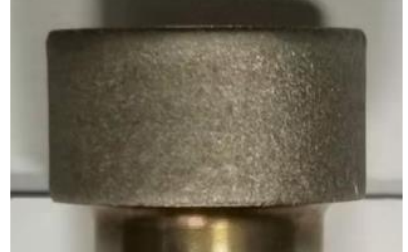

(c) $500 \mathrm{rpm}$

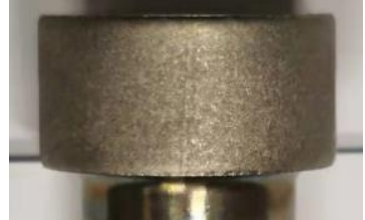

(d) $700 \mathrm{rpm}$

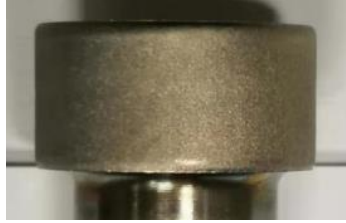

(e) $900 \mathrm{rpm}$

Fig. 13 Surface morphology of workpiece machined at different rotating speeds

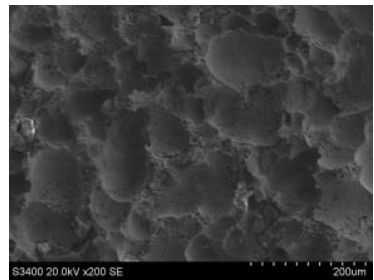

(a) $100 \mathrm{rpm}$

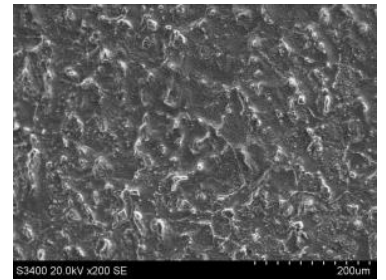

(b) $300 \mathrm{rpm}$

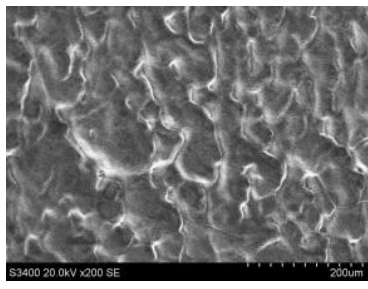

(c) $500 \mathrm{rpm}$

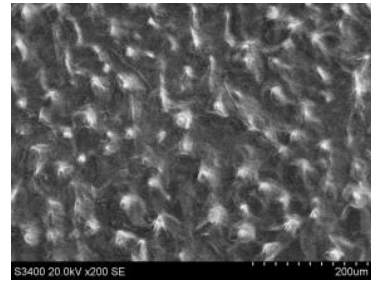

(d) $700 \mathrm{rpm}$

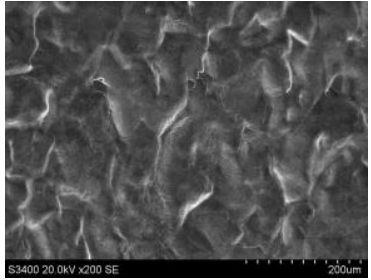

(e) $900 \mathrm{rpm}$

Fig. 14 Micro morphology of workpiece surface with different rotating speeds

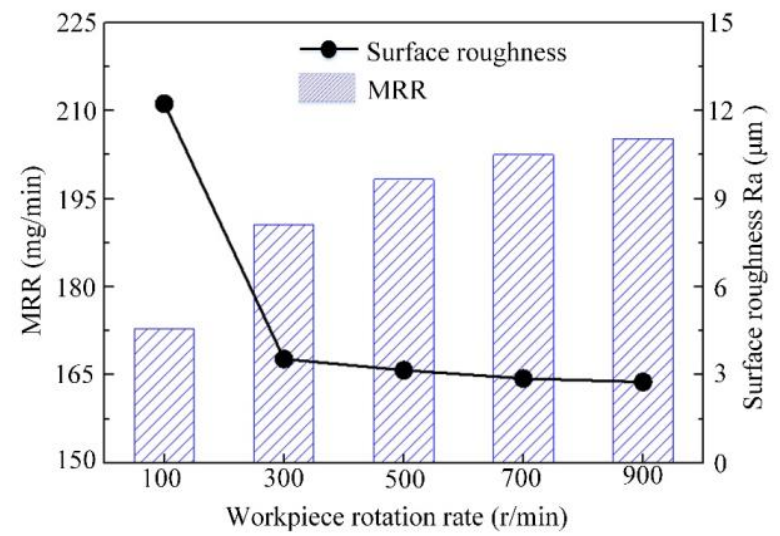

Fig. 15 Effect of workpiece rotating speed on MRR and surface roughness

The experimental results demonstrated that the machined surface was a dense honeycomb and the surface roughness was Ra $12.24 \mu \mathrm{m}$ for a workpiece rotating speed of $100 \mathrm{rpm}$. With 
increasing rotating speed, the machining time for each rotation cycle was shortened, which led to a reduction of the surface roughness and improved MRR.

\section{(3) Tool electrode feed rate}

Different feed rates for the tool electrode were selected for the experiment. The initial machining gap was $0.3 \mathrm{~mm}$, the machining voltage was $32 \mathrm{~V}$, the workpiece speed was $900 \mathrm{rpm}$, the electrolyte pressure was $0.8 \mathrm{MPa}$, and the machining time was $7 \mathrm{~min}$. The macroscopic morphology of the machined samples was shown in Fig. 16. The micro morphology of the machined surfaces of the samples were observed via SEM, as shown in Fig. 17. The relationship between the MRR, surface roughness, and tool cathode feed rate is shown in Fig. 18.

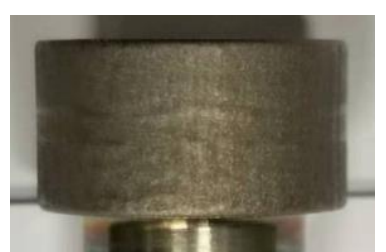

(a) $70 \mu \mathrm{m} / \mathrm{min}$

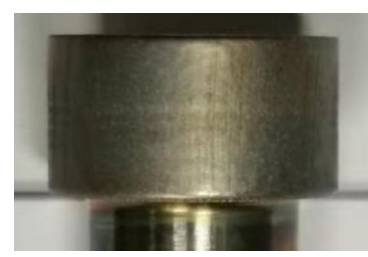

(b) $90 \mu \mathrm{m} / \mathrm{min}$

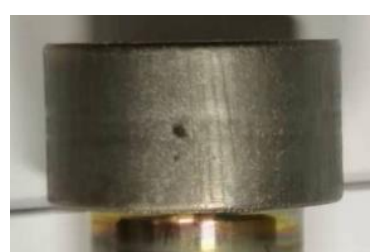

(c) $110 \mu \mathrm{m} / \mathrm{min}$

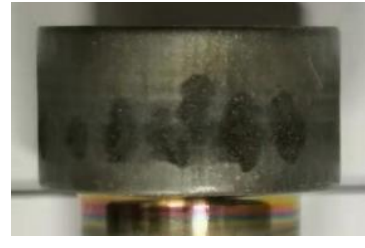

(d) $130 \mu \mathrm{m} / \mathrm{min}$

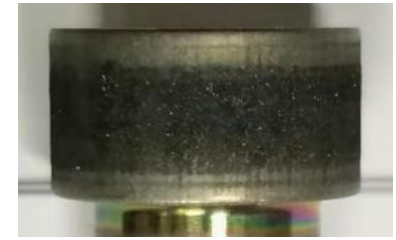

(e) $150 \mu \mathrm{m} / \mathrm{min}$

Fig. 16 The macroscopic morphology of the machined samples at different feed rates

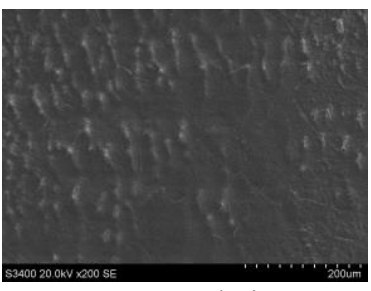

(a) $70 \mu \mathrm{m} / \mathrm{min}$

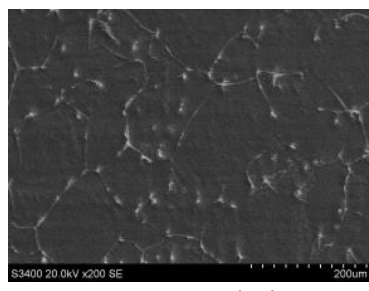

(b) $90 \mu \mathrm{m} / \mathrm{min}$

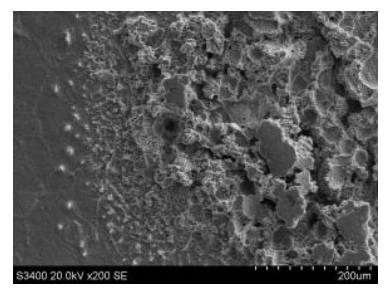

(c) $110 \mu \mathrm{m} / \mathrm{min}$

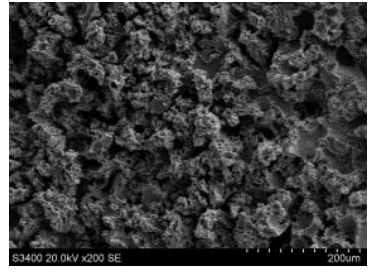

(d) $130 \mu \mathrm{m} / \mathrm{min}$

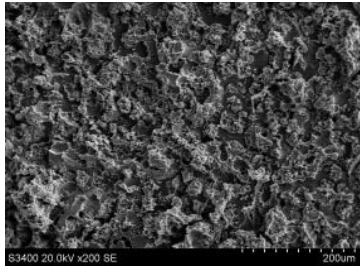

(e) $150 \mu \mathrm{m} / \mathrm{min}$

Fig. 17 The micro morphology of the machined surfaces of the samples at different feed rates 


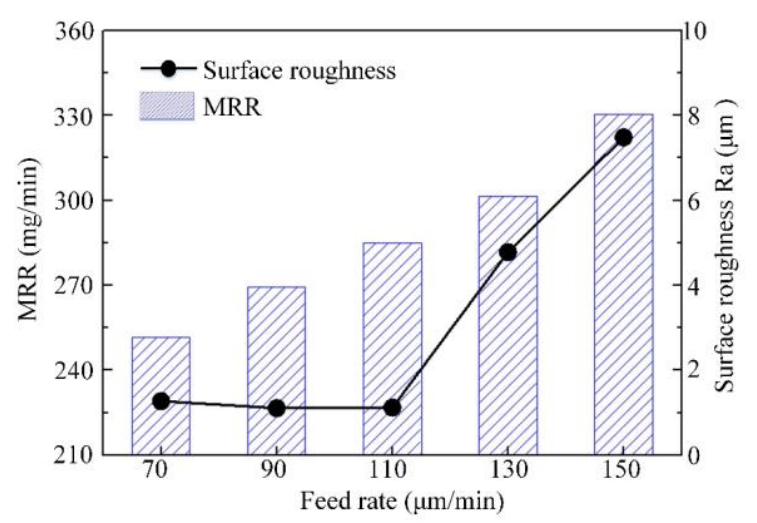

Fig. 18 Effect of feed rate on MRR and surface roughness

When the feed rate was 70,90 , and $110 \mu \mathrm{m} / \mathrm{min}$, the surface roughness of the machined samples remained almost the same (Fig. 18) but the surface morphology of the machined samples varied significantly (Fig. 16a-c and Fig. 17a-c). When the feed rate was $70 \mu \mathrm{m} / \mathrm{min}$, the machined surface was smooth and had no obvious defects. For a feed rate of $90 \mu \mathrm{m} / \mathrm{min}$, the grain boundaries precipitated on the machined surface, which indicated that the electrochemical dissolution rate was not consistent. For a feed rate of $110 \mu \mathrm{m} / \mathrm{min}$, a small black spot appeared on the surface of the workpiece. Using SEM, it was found that the morphology of the small black spot was loose and porous, and it was completely different to that of the surrounding area. When the feed rate was 130 and $150 \mu \mathrm{m} / \mathrm{min}$, a large area of black material appeared on the surface of the workpiece, as shown in Fig. 16d and 16e. Based on the SEM results, the black material was crisp and porous, and it had a similar micro morphology to the small black spots in Fig. 17c, as shown in Fig. 17d and 17e. The black material caused the roughness of the machined surface to increase significantly. From the EDX results, the main elements were determined to be carbon and oxygen (Fig. 19), and it could be inferred that the black material was composed of metal compounds containing carbon and oxygen. From the above analysis, it can be seen that the tool cathode feed rate should not be too high for electrolyte jet ECT of TB6 titanium alloy. The appropriate feed rate should be selected and a large machining gap should be maintained to ensure timely removal of the electrolytic products. To achieve uniform dissolution of the workpiece surface, a feed rate of $70 \mu \mathrm{m} / \mathrm{min}$ was used for the subsequent sample machining experiments.
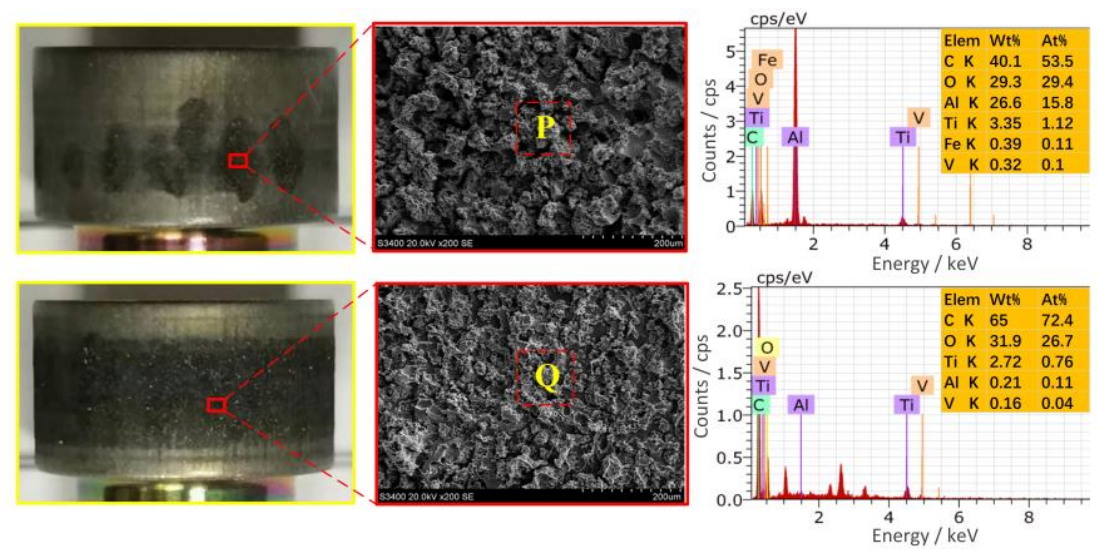

Fig. 19 EDX detection of black matter on the machined workpiece surface 
In addition, MRR increased with increasing tool electrode feed rate because of increased machining electric-field strength. When the feed rate of the tool electrode was $150 \mu \mathrm{m} / \mathrm{min}$, the MRR was at a maximum $(330.5 \mathrm{mg} / \mathrm{min})$.

\subsection{TB6 Titanium alloy machining}

Using TB6 titanium alloy as the object for machining, different rotating samples were machined. The goal was to remove $\sim 1 \mathrm{~mm}$ in the radial direction. Figure 20 shows the relationship between the relative position between the tool electrode and samples. The electrolyte was a 10 wt $\% \mathrm{NaNO}_{3}$ solution, the electrolyte temperature was $30^{\circ} \mathrm{C}$, the machining voltage was $32 \mathrm{~V}$, the initial machining gap was $0.3 \mathrm{~mm}$, the feed rate of the tool electrode was $70 \mu \mathrm{m} / \mathrm{min}$, the rotation speed of the samples was $900 \mathrm{rpm}$, and the electrolyte pressure was $0.8 \mathrm{MPa}$. Figure 21 shows the machining results for the different samples. For a sample with a cylindrical surface (Fig. 21a), the MRR was $196.7 \mathrm{mg} / \mathrm{min}$, the surface roughness was Ra $3.368 \mu \mathrm{m}$, and the roundness error was $0.012 \mathrm{~mm}$. For the sample with a curved profile surface (Fig. 21b), the MRR was $186.6 \mathrm{mg} / \mathrm{min}$, the surface roughness was $\mathrm{Ra} 4.218 \mu \mathrm{m}$ and the radius of the arc contour changed from 15 to $15.003 \mathrm{~mm}$. For the conical surface sample (Fig. 21c), the MRR was $184.7 \mathrm{mg} / \mathrm{min}$, the surface roughness was Ra $2.414 \mu \mathrm{m}$, and the taper of the machined surface changed from $5.711^{\circ}$ to $5.710^{\circ}$. It could be seen that the surface roughness of the machined samples was low and the contour shape accuracy of the machined samples was high, which indicated that good machining surface quality and machining accuracy could be obtained.

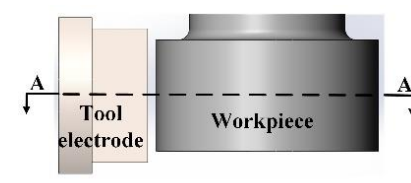

A-A

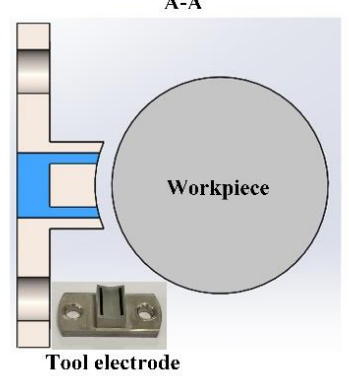

(a) Cylindrical surface

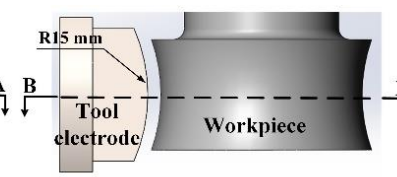

B-B

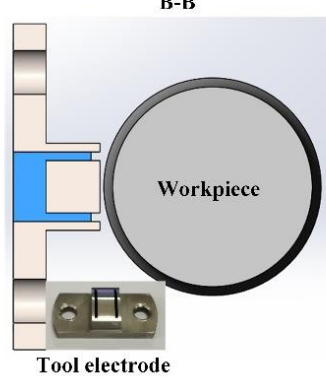

(a) Arc surface

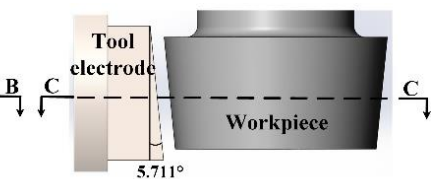

C-C

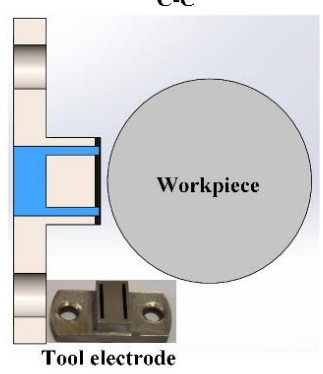

(a) Conical surface

Fig. 20 The relative position relationship between the tool electrode and different samples 


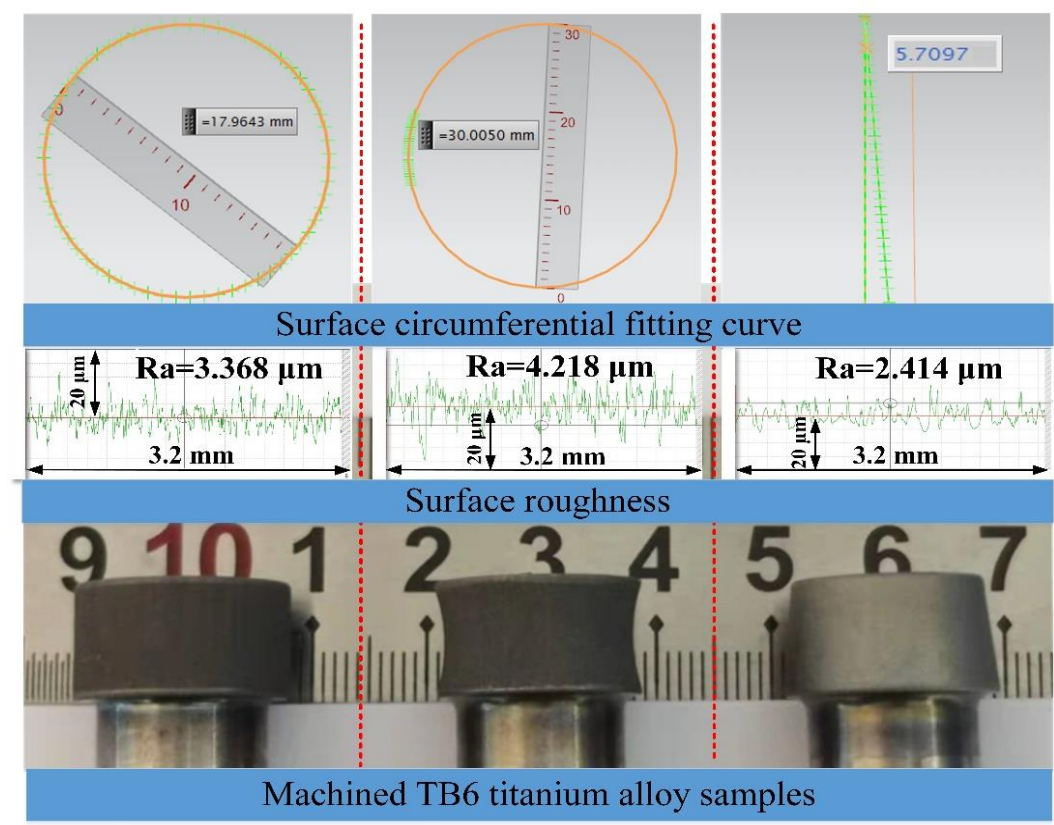

$\begin{array}{lll}\text { (a) Cylindrical surface } & \text { (b) Arc surface } & \text { (c) Conical surface }\end{array}$

Fig. 21 Machining results of TB6 titanium alloy samples

\section{Conclusion}

To realize high-quality machining of revolving titanium alloy components, flow field simulation analysis was carried out and different flow field schemes for machining revolving parts were designed and optimized. Experiments on electrolyte jet ECT of TB6 titanium alloy were conducted. The influence of different machining parameters on the machining efficiency and surface quality was analyzed. Finally, different titanium alloy samples with different shapes were machined.

The main aspects of this work include:

(1) Flow field simulations were carried out on electrolyte jet ECT of revolving parts. Optimizing the number and layout of outlet slit could restrict the electrolyte and force the electrolyte to fill the machining gap, improving the machining electric-field intensity and machining efficiency.

(2) The key machining parameters were optimized via electrochemical machining experiments using electrolyte jet ECT of TB6 titanium alloy. The experimental results showed that a high machining voltage and feed rate was helpful to improve the machining efficiency; however, a too high feed rate may deteriorate the machined surface quality.

(3) Finally, three kinds of revolving TB6 titanium alloy samples with different structures were machined via electrolyte jet ECT. The machining accuracy and surface roughness were notably good, which demonstrated that this method has potential application for industrial production.

\section{Declaration of Competing Interest}

The authors declare that they have no known competing financial interests or personal relationships that could influence the work reported in this paper. 


\section{Acknowledgments}

The work described in this study was supported by the National Natural Science Foundation of China (No. 91860208) and Natural Science Foundation of Jiangsu Province of China (No. BK20210755) .

\section{References}

[1] Wang D, Wang Q, Zhang J, Le H, Zhu Z, Zhu D. (2021) Counter-rotating electrochemical machining of intensive cylindrical pillar array using an additive manufactured cathode tool. Int J Mech Sci: 106653 .

[2] Ge Y, Zhu Z, Zhu D, Wang D. (2018) Electrochemical machining of a convex strips structure on a revolving part by using site directed power interruption. Chinese J Aeronaut 31(10):2049-2056.

[3] Liu Y, Qu N. (2020) Investigation on the performance of macro electrochemical machining of the end face of cylindrical parts. Int J Mech Sci 169:105333.

[4] Wang D, Li J, He B, Zhu D. (2019) Analysis and control of inter-electrode gap during leveling process in counter-rotating electrochemical machining. Chinese J Aeronaut 32(11):2557-2565.

[5] Li J, Wang D, Zhu D, He B. (2020) Analysis of the flow field in counter-rotating electrochemical machining. J Mater Process Tech 275:116323.

[6] Wang J, Xu Z, Wang J, Xu Z, Zhu D. (2021) Electrochemical machining of blisk channels with rotations of the cathode and the workpiece. Int J Mech Sci 208:106655.

[7] Cao W, Wang D, Ren Z, Zhu D. (2020) Evolution of convex structure during counter-rotating electrochemical machining based on kinematic modeling. Chinese J Aeronaut 34(3):39-49.

[8] Cao W, Wang D, Zhu D. (2020) Modeling and experimental validation of interelectrode gap in counter-rotating electrochemical machining. Int J Mech Sci 187:105920.

[9] Pa PS. (2008) Effective form design of electrode in electrochemical smoothing of end turning surface finishing. J Mater Process Tech 195(1-3):44-52.

[10] Eltaweel TA. (2008) Modelling and analysis of hybrid electrochemical turning-magnetic abrasive finishing of $6061 \mathrm{Al} / \mathrm{Al}^{2} \mathrm{O}_{3}$ composite. Int J Adv Manuf Tech 37(7-8):705-714.

[11] Wang YK, Li X, Chen H, Wang ZL, Shan DB. (2010) Microelectrode Fabrication by Electrochemical Turning. Key Engineering Materials 455:269-273.

[12] Haridy S, Gouda SA, Zhang W. (2011) An integrated framework of statistical process control and design of experiments for optimizing wire electrochemical turning process. Int J Adv Manuf Tech 53(1-4):191-207.

[13] Kunieda M, Mizugai K, Watanabe S, Shibuya N, Iwamoto N. (2011) Electrochemical micromachining using flat electrolyte jet. CIRP Ann Manuf Technol 60(1):251-254.

[14] Pa, P. S. (2013) A Magnetic-Assistance System as a Super Finishing Following Turning Machining. Adv Mater Res 683:937-940.

[15] Martin A, Hackert-Oschtzchen M, Lehnert N, Schubert A. (2018) Analysis of the fundamental removal geometry in electrochemical profile turning with continuous electrolytic free jet. Procedia CIRP 68:466-470.

[16] Sharma V, Srivastava I, Tyagi A, Jain VK, Ramkumar J. (2018) Theoretical and Experimental Investigations into Wire Electrochemical Turning (Wire-ECTrg) Process Using Finite Element Method. J Electrochem Soc 165:773-783. 
[17] Sharma V, Patel S, Jain VK, Ramkumar J, Tyagi A. (2018) Wire Electrochemical Threading: A Technique for Fabricating Macro/Micro Thread Profiles. J Electrochem Soc 165:397-405.

[18] Kendall T, Bartolo P, Gillen D, Diver C. (2019) A review of physical experimental research in jet electrochemical machining. Int J Adv Manuf Tech 105(1):651-667.

[19] Zanjani MY, Kashani HG, Mirahmadi A. (2013) Improvement of electrochemical turning for machining complex shapes using a simple gap size sensor and a tubular shape tool. The International Journal of Advanced Manufacturing Technology 69(1-4):375-381.

[20] Ge YC, Zhu Z, Ma Z, Wang D. (2018) Large allowance electrochemical turning of revolving parts using a universal cylindrical electrode. J Mater Process Tech 258:89-96.

[21] Ge YC, Zhu Z, Zhu Y. (2019) Electrochemical deep grinding of cast nickel-base superalloys. J Mater Process 47:291-296.

[22] Ge Y, Zhu Z, Wang D, Ma Z, Zhu D. (2019) Study on material removal mechanism of electrochemical deep grinding. J Mater Process Tech 271:510-519.

[23] Ge YC, Zhu Z, Zhou M, Wang D. (2018) Tool Design and Experimental Study on Electrochemical Turning of Nickel-Based Cast Superalloy. J Electrochem Soc 165(5):E162-E170.

[24] Fu XQ, Xian JY, Kang M, Xiao MH. (2013) Research on the Process of numerical control electrochemical turning based on finite element method. Adv Mater Res 764:95-101.

[25] Liu W, Ao S, Li Y, Liu Z, Zhang H, Manladan S M, Luo Z, Wang Z. (2017) Effect of Anodic Behavior on Electrochemical Machining of TB6 Titanium Alloy. Electrochim Acta 233:190-200.

[26] Liu W, Kunieda M, Luo Z. (2021) Three-dimensional simulation and experimental investigation of electrolyte jet machining with the inclined nozzle. J Mater Process Tech 297:117244.

[27] Ge Y, Zhu Z, Wang D. (2017) Electrochemical Dissolution Behavior of the Nickel-Based Cast Superalloy K423A in $\mathrm{NaNO}_{3}$ Solution. Electrochim Acta 253:379-389.

[28] Zhang B, Wang J, Wu B, Guo X W, Wang Y J, Chen D, Zhang Y C, Du K, Oguzie E E, Ma X L. (2018) Unmasking chloride attack on the passive film of metals. Nat Commun 9(1):2559. 